\title{
Mental health professionals' knowledge, skills and attitudes on domestic violence and abuse in the Netherlands: cross-sectional study
}

Roos E. Ruijne, Astrid M. Kamperman, Kylee Trevillion, Carlo Garofalo, Femke E. Jongejan, Stefan Bogaerts, Louise M. Howard and Niels L. Mulder

\section{Background}

Despite the high prevalence of domestic violence and abuse (DVA) among patients with psychiatric conditions, detection rates are low. Limited knowledge and skills on DVA in mental healthcare $(\mathrm{MHC})$ professionals might contribute to poor identification.

\section{Aims}

To assess the level of, and factors associated with, DVA knowledge and skills among MHC professionals.

\section{Method}

A total of 278 professionals in Dutch MHC institutions completed a survey assessing factual knowledge, perceived knowledge, perceived skills and attitudes about DVA.

\section{Results}

On average, low scores were reported for perceived skills and knowledge. MHC professionals in primary care scored higher than those working with individuals with severe mental illness $(P<0.005)$. Levels of factual knowledge were higher; levels of attitudes moderate. Previous training was positively associated with skills (odds ratios $(O R)=3.0$ ) and attitudes $(O R=2.7)$. Years of work was negatively associated with factual knowledge (OR = 0.97). Larger case-loads predicted higher scores on skills $(\mathrm{OR}=2.1)$.

\section{Conclusions}

Training is needed, particularly for clinicians working with patients with severe mental illness.

\section{Declaration of interest}

None.

\section{Keywords}

Domestic violence and abuse; community mental health teams; cross-sectional study.

\section{Copyright and usage}

(c) The Royal College of Psychiatrists 2019. This is an Open Access article, distributed under the terms of the creative commons Attribution-NonCommercial-NoDerivatives licence (http://creativecommons.org/licenses/by-nc-nd/4.0/), which permits noncommercial re-use, distribution, and reproduction in any medium, provided the original work is unaltered and is properly cited. The written permission of Cambridge University Press must be obtained for commercial re-use or in order to create a derivative work.
Domestic violence and abuse (DVA) is a prevalent public health issue affecting societies worldwide. The World Health Organization estimates that one in three women experiences domestic or sexual violence or both during her lifetime. ${ }^{1}$ DVA in this study is defined as 'any incident of threatening behavior, violence or abuse (psychological, physical, sexual, financial or emotional) between adults who are or have been an intimate partner, family member, friend or otherwise closely related (i.e. a care taker or roommate)'. ${ }^{2}$ This definition differs from the World Health Organization definition as it includes elderly abuse but excludes child abuse. ${ }^{3}$ DVA affects every layer of society. However, there are some specific risk factors associated with DVA victimisation, including female gender, younger age, substance misuse, financial difficulties, social isolation, history of child abuse, witnessing DVA as a child, poverty and having a mental disorder. ${ }^{4-8} \mathrm{~A}$ recent study in the Netherlands showed that patients with psychiatric conditions are six times more likely to be victims of DVA compared with the general population, ${ }^{9}$ confirming that this group are at particularly high risk of victimisation. Victimisation from DVA can have severe consequences. Apart from physical injuries such as fractures and chronic somatic conditions such as chronic back pain, DVA is also associated with the exacerbation and development of a wide range of psychological problems, such as anger, peritraumatic emotions, antisocial behaviour and psychiatric illnesses. ${ }^{7,10-12}$ These psychiatric illnesses can vary from depression and post-traumatic stress disorder to psychosis. ${ }^{10,13,14}$ Thus, in patients already presenting with psychiatric problems, the occurrence of DVA may worsen their condition, in turn interfering with professional interventions.
Despite the high prevalence of DVA and the serious consequences for the physical and mental health of patients with psychiatric conditions, detection rates for DVA among mental healthcare (MHC) professionals remain low. ${ }^{15-17}$ Reasons for failing to detect DVA vary. ${ }^{18,19}$ When probed, clinicians and MHC providers suggest that a lack of basic knowledge and skills on DVA, such as how to recognise and support a victim of DVA, and fear of offending or endangering the victim may also contribute to ignoring risk factors and a low detection rate. ${ }^{18,19}$ In recent years, DVA has gained more attention worldwide. Since 2014, legislation and guidelines for clinicians have been developed in the Netherlands ${ }^{20,21}$ and the Dutch government has promoted these guidelines in the media and in clinical settings, with advertisements, courses and seminars. A substantial part of these measures aims to improving knowledge and changing attitudes towards victims. However, the actual status of knowledge, skills and attitudes regarding DVA among MHC professionals, both those working in primary $\mathrm{MHC}$ and specialised MHC services for patients with severe mental illness (SMI) in the Netherlands, is unknown.

\section{Objectives}

In this study, we aimed to assess the level of and associations between factual and perceived knowledge on DVA, perceived skills for managing DVA and attitudes towards DVA among MHC professionals. First, we compared professionals working in primary MHC (treating patients with mild psychopathology) with professionals working in (F)ACT ((flexible) Assertive Community 
Treatment) teams (treating patients with severe mental illness (SMI)). Next, we assessed how these factors were associated with specific characteristics of the professionals, such as discipline, work experience and gender.

\section{Method}

\section{Design}

A cross-sectional survey on DVA was conducted among the clinicians of the community MHC teams of three MHC institutions. The current study is embedded in a cluster randomised controlled trial on DVA detection in MHC: Better Reduction through Assessment of Violence and Evaluation (the BRAVE study, registration: ISRCTN14115257). ${ }^{22}$ The protocol and addendum were approved by the Medical Ethics Committee of the Erasmus Medical Centre (MEC 2015-409). Participation in the survey was voluntary, and consent was assumed from participation. According to the Medical Ethics Committee a formal informed consent was not deemed necessary. All clinicians had received an information letter regarding the survey beforehand. This study is conducted in accordance with the Declaration of Helsinki (1964), as amended in Edinburgh (2000).

\section{Participants and setting}

All MHC professionals working in 34 community MHC teams were invited to participate. Each team consists of approximately ten professionals from diverse disciplines, for example psychiatrists, psychologists, psychiatric nurses, specialised nurses, social workers and occupational therapists. The participating MHC institutions (i.e. Parnassia, Indigo and Bavo Europoort) are located in Rotterdam and The Hague, two large cities in the urbanised area in the Netherlands. The included teams at Parnassia, The Hague and Bavo Europoort, Rotterdam offer outreaching intensive case management care, also known as (F)ACT care, ${ }^{23}$ for patients with SMI requiring medication and (in acute situations) psychiatric hospital admission (in this study shortened to SMI care). (Psychiatric) nurses, social workers and a psychiatrist form the core of these SMI teams. The teams of Indigo, Rotterdam Rijnmond offer short-term (maximum of ten sessions) primary out-patient care for patients with less severe mental health problems. Psychologists are more prominent in the Indigo community MHC teams. Parnassia, Indigo and Bavo Europoort are the largest MHC service providers in the Rotterdam and The Hague area. Together they provide care to a service area of 2.5 million inhabitants.

\section{Main outcome instrument: the BRAVE survey}

To assess the readiness of MHC professionals to manage DVA in patients with psychiatric conditions, we developed the BRAVE survey. The BRAVE survey was developed for our specific setting but was informed by the Physician Readiness to Manage Intimate violence Survey (PREMIS), ${ }^{24}$ the adapted PREMIS for community mental health professionals in the $\mathrm{UK}^{25}$ and the PROTECT questionnaire, a knowledge survey on human trafficking designed for health professionals. ${ }^{26}$ These instruments are structured questionnaires, validated to assess physician's readiness to manage violence.

To enhance response rates, we aimed for a short questionnaire with a maximum administration time of $10 \mathrm{~min}$. To do so, we originally started with a pool of 67 potential items derived from a previous knowledge survey to probe DVA knowledge, skills and attitudes towards DVA victims. All items were forward translated into Dutch by two bilingual (English and Dutch) researchers working independently. Discrepancies were discussed until consensus was reached. Items were back-translated into English by a professional native speaker. Authors (R.E.R. and F.E.J.) reviewed the forward and backward translation. Items were adapted to the Dutch MHC setting.

Next, we selected items from this pool using a stepwise procedure (see van Knippenberg et $a l^{27}$ for a similar procedure), using anonymised data from an earlier study on knowledge, attitudes and preparedness of psychiatrists and psychiatric nurses working within a south London Mental Health National Health Service Trust $(n=131) .{ }^{17,25}$ First, items that had elicited many missing responses ( $>25 \%$ missing values) or with zero variance were excluded. Next, subscale scores were calculated. Using a stepwise backward multivariate regression model, items that did not contribute to the variance of the subscale were excluded. The remaining items had to explain more than $95 \%$ of the variance (adjusted $\left.R^{2}>0.95\right)$ of the original subscale score. Multicollinearity of the remaining items was checked with inter-item correlation $(\leq 0.80)$, opposite signs for item-total correlation and regression weight, and variance inflation factor $(<10)$. After its development, the questionnaire was evaluated using clinical judgement on the interpretability of the subscales. To ensure comprehensibility, we adopted the lay out of the PROTECT questionnaire. Finally, the questionnaire was tested with five volunteers on comprehensibility and time taken to administer, resulting in minor changes in phrasing and lay out. Test-retest reliability of the subscale scores was assessed in a convenience sample of 20 MHC professionals over 3-5 day period. ${ }^{28}$ We calculated the intraclass correlation estimate (ICC) and their $95 \%$ confidence interval. Internal consistency was estimated using Cronbach's alpha coefficient.

The BRAVE survey assesses readiness to handle DVA in patients with psychiatric conditions by MHC professionals, consisting of 54 questions in five sections.

(a) Respondent characteristics. This assesses basic demographic and professional information of the respondent, such as number of years working as an MHC professional and previous training.

(b) Perceived skills to manage DVA. This contains seven statements with Likert scales, ranging from zero (not prepared) to four (very prepared), about the extent to which they feel prepared to handle, judge or follow-up on a particular DVArelated situation (for instance: 'I feel prepared to appropriately respond to disclosures of domestic violence'). The subscale score may range from 0 to 28 . ICC $=0.99$ ( $95 \%$ CI $0.95-1.00$ ); Cronbach's alpha 0.90 .

(c) Perceived knowledge on DVA. This consists of three statements where respondents rate their knowledge and skills to handle DVA using a five-point Likert scale. The subscale score may range from 0 to 12. An example of a statement is 'How much do you feel you know about perpetrators of domestic violence or abuse?'. ICC $=0.97$ (95\% CI 0.57-1.00); Cronbach's alpha 0.74 .

(d) Factual knowledge about DVA. This consists of 15 multiple choice questions. Respondents answer these questions with true or not true (for instance: 'Depressive symptoms are a warning sign that a patient may have been a victim of domestic violence or abuse. True or Not True?'). The last question in this section tests understanding of the stages of change model. ${ }^{29}$ The respondent is asked to assign the correct theoretical stage (i.e. precontemplation, contemplation, preparation, action, maintenance or termination) to a series of victim actions (i.e. begins making plans for leaving abusive partner; denies there is a problem; begins thinking the abuse is not their fault; continues changing behaviours; obtain injunction(s) for protection). The number of correct answers is scored. The subscale scores may range from 0 to 19 . ICC $=0.99$ (95\% CI 0.997-1.00). 
As we did not assume a single latent trait, we did not determine the internal reliability of this subscale. ${ }^{30}$

(e) Attitudes towards DVA. This consists of 17 statements tapping attitudes on a range of DVA-related concepts, such as usefulness of supporting victims, empathy for a victim and the dilemmas a victim may face (for example 'If a patient refuses to discuss the abuse, a professional can only treat the patient's symptoms'), but also on responsibility and ability to support a victim and manage DVA in their team and as an individual (for example 'A professional ought to screen every patients on DVA'). Items are rated on five-point Likert scale (from 0 , do not agree to 4 , fully agree), resulting in a subscale score ranging from 0 to 68 . A high score indicates a high level of victim understanding, self-efficacy and staff preparation. ICC $=0.97$ (95\% CI 0.97-0.99); Cronbach's alpha 0.59.

\section{Data collection}

Data collection took place in the period February to April 2016 (Bavo Europoort, Rotterdam), February to May 2017 (Parnassia, The Hague), and June to September 2017 (Indigo, Rotterdam). The survey was offered digitally via an email with a link to the web-platform hosting the survey (LimeSurvey) and on paper via the researchers handing out the paper version to the staff. Participants were sent a reminder by email every 2 weeks. Both Bavo Europoort, Rotterdam and Parnassia, The Hague participated in the BRAVE trial and were offered the survey as a baseline assessment.

All MHC professionals $(n=358)$ working in 34 community MHC teams were invited to complete the survey (Bavo Europoort ( $n=200 ; 18$ teams), Parnassia $(n=60 ; 6$ teams); Indigo $(n=98$; 10 teams)). Of these, 278 completed the survey (overall response rate $78 \%(278 / 358))$. The response rate was $65.3 \%$ (64/98) among Indigo, 79.5\% (159/200) among Bavo Europoort and 91.7\% (55/60) among Parnassia MHC professionals. Reasons for non-response were having left the participating MHC institutions (19\%), chronic absence because of illness (7\%), maternity leave (3\%) or retirement (1\%). We found no evidence for selective non-response based on gender $\left(\chi^{2}(1)=0.592 ; P=0.442\right)$. However, psychiatrists and social workers were more often non-responders compared with nurses and psychologists $\left(\chi^{2}(5)=16.077 ; P=0.007\right)$.

\section{Statistical methods}

Differences regarding the demographic and professional characteristics of the professionals working in primary care and SMI care (i.e. (F)ACT teams) were estimated using $t$-tests and Mann-Whitney $U$-tests for continuous variables, and with Chi-square test and Fisher's exact test for categorical variables. Correlations between the subscales of the survey were calculated using Spearman's and interpreted as follows: $r>0.70$ very large, $r$ between 0.50 and 0.70 large, $r$ between 0.50 and 0.30 moderate and $r<0.30$ as a weak effect. ${ }^{31}$ Next, univariate logistic regression analysis was used to test the association between demographic and professional characteristics and perceived skills, factual knowledge and attitudes. Significant predictors $(P<0.05)$ were simultaneously entered in a multivariate model. We present the odds ratios (OR) and accompanying 95\% confidence intervals. For the purpose of the logistic regression analyses, scores of the BRAVE subscales were dichotomised using median split. Based on the high interrelationship between perceived knowledge and perceived skills, we refrained from performing these analyses for perceived knowledge separately.

Normality of the data was inspected visually using histograms and Q-Q plots, and statistically using Kolmogorov-Smirnov tests. Less than $1 \%$ of data were missing. Missing outcome data were replaced by the series median scores. Cases with missing predictor data were excluded from the analysis.

\section{Results}

As shown in Table 1, the majority of MHC professionals were women particularly in primary MHC. In primary MHC, most professionals were psychologists by training. In the teams providing care to patients with SMI, far fewer psychologists were employed $(10 \% v .50 \%)$ and there was a more prominent presentation of psychiatric nurses (36\% v. 19\%) and social workers (14\% v. $2 \%)$. In line with the assertive outreach methodology of the participating (F)ACT teams, case-loads were small (i.e. mostly 20-39 patients per month). In primary care most clinicians saw over 60 patients per month. More MHC professionals working in primary care than those working in (F)ACT teams had ever received training about DVA at some point in the past. However, more professionals in (F)ACT teams, had received training about DVA in the previous 6 months (i.e. in-service training ranging from $1 \mathrm{~h}$ presentations and short web courses to multiple day face-to-face courses on DVA) compared with MHC professions working in primary care.

Overall, the mean scores of both primary and (F)ACT MHC clinicians on the BRAVE scales measuring perceived skills to manage DVA and perceived knowledge on DVA were low, although with significantly higher scores for primary MHC clinicians in both domains. Mean scores for factual knowledge were higher, whereas the mean score of the attitudes scale was in the middle region of the scale. We found no evidence of differences in levels of factual knowledge in primary $\mathrm{MHC}$ and (F)ACT MHC clinicians. Additionally, no difference in attitudes regarding victim understanding, self-efficacy and staff preparation were found.

\section{Correlations between scales}

Perceived skills to manage DVA was strongly correlated with perceived knowledge about DVA $(r=0.61, P<0.001)$. Correlation between perceived skills and attitudes was moderate $(r=0.44$, $P<0.001)$. We also found a moderate correlation between perceived knowledge with attitudes $(r=0.33, P<0.001)$. A weak correlation was found between perceived knowledge and factual knowledge $(r=0.17, P=0.005)$. No significant correlation was found between factual knowledge and perceived skills to manage DVA, and between factual knowledge and attitudes towards DVA.

\section{Predictors of DVA skills, knowledge and attitudes}

The associations with perceived skills to manage DVA are presented in Table 2. Univariate analyses showed that clinicians who saw fewer than 40 patients per month perceived themselves less skilled in managing DVA than colleagues who see 60 or more patients per month. Higher levels of perceived skills to manage DVA were found in clinicians who had previously been trained in DVA. We found that primary MHC clinicians feel more skilled to manage DVA than clinicians working in (F)ACT teams. Size of the caseload, previous training and MHC service remained significant predictors when analysed in a multivariate model. In the multivariate regression model, the highest score was found for clinicians with a case-load of between 40 and 59 patients per month. Odds ratios revealed a strong association between perceived skills to manage DVA, previous DVA training and working in primary MHC.

In our univariate analyses, factual knowledge was negatively associated with age and working experience, showing that factual knowledge was greater among younger clinicians, and clinicians with fewer years of professional experience (results are presented in Table 3). Also, in comparison with psychiatric nurses, 
Table 1 Demographic and professional characteristics of the respondents $(n=278)$ and scores on the scales of the Better Reduction through Assessment of Violence and Evaluation (BRAVE) survey

\begin{tabular}{|c|c|c|c|c|c|c|c|}
\hline & \multicolumn{2}{|c|}{ Teams } & \multicolumn{5}{|c|}{ Test statistics } \\
\hline & $\begin{array}{l}\text { Primary care } \\
(n=64)\end{array}$ & $\begin{array}{l}\text { SMI care } \\
(n=214)\end{array}$ & $\chi^{2}$ (d.f.) & $t$-test (d.f.) & $U$-test & $Z$-test & $P$ \\
\hline \multicolumn{8}{|l|}{ Characteristics } \\
\hline Gender, (male): $n$ (\%) & $10(16)$ & 79 (37) & $10.26(1)$ & - & - & - & 0.001 \\
\hline Age, mean (s.d.) & $45.6(10.8)$ & $43.0(12.2)$ & - & $1.48(272)$ & - & - & 0.138 \\
\hline Discipline, $n(\%)$ & & & $52.74(5)$ & - & - & - & $<0.001$ \\
\hline Psychiatrist or resident & 5 (8) & $24(11)$ & - & - & - & - & - \\
\hline Psychologist & $32(50)$ & $22(10)$ & - & - & - & - & - \\
\hline Psychiatric nurse & $8(13)$ & $31(15)$ & - & - & - & - & - \\
\hline General nurse & $12(19)$ & $78(36)$ & - & - & - & - & - \\
\hline Social worker & 1 (2) & 30 (14) & - & - & - & - & - \\
\hline Other & $6(9)$ & $29(14)$ & - & - & - & - & - \\
\hline Professional experience in years, median (IQR) & $12(8-24)$ & $12(7-24)$ & - & - & - & -0.739 & 0.460 \\
\hline Case-load (per month), $n$ (\%) & & & $20.33(4)$ & - & - & - & $<0.001$ \\
\hline No patients & $0(-)$ & $1(0.5)$ & - & - & - & - & - \\
\hline$<20$ patients & 1 (2) & $16(7.5)$ & - & - & - & - & - \\
\hline 20-39 patients & $13(20)$ & $80(37.4)$ & - & - & - & - & - \\
\hline 40-59 patients & $14(22)$ & $51(23.8)$ & - & - & - & - & - \\
\hline$\geq 60$ patients & $36(56)$ & $56(26.1)$ & - & - & - & - & - \\
\hline Missing & - & $10(4.7)$ & - & - & - & - & - \\
\hline \multicolumn{8}{|l|}{ Previous DVA training, $n$ (\%) } \\
\hline Yes, ever & $58(91)$ & $161(75)$ & $6.98(1)$ & - & - & - & 0.008 \\
\hline Yes, $<6$ months ago & $3(4)$ & $42(20)$ & $8.10(1)$ & - & - & - & 0.004 \\
\hline \multicolumn{8}{|l|}{ BRAVE scales (theoretical range) } \\
\hline \multicolumn{8}{|l|}{ Perceived skills (0-28) } \\
\hline Mean (s.d.) & $9.3(5.2)$ & $4.9(3.2)$ & - & - & 3082.5 (273) & - & $<0.001$ \\
\hline Median (IQR) & $9.0(6.0-11.8)$ & $4.0(3.0-7.0)$ & - & - & - & - & - \\
\hline \multicolumn{8}{|l|}{ Perceived knowledge (0-12) } \\
\hline Mean (s.d.) & $2.9(2.2)$ & $2.0(1.9)$ & - & - & 5310.5 (278) & - & 0.005 \\
\hline Median (IQR) & $2.0(1.0-4.0)$ & $2.0(1.0-3.0)$ & - & - & - & - & - \\
\hline \multicolumn{8}{|l|}{ Factual knowledge (0-19) } \\
\hline Mean (s.d.) & $13.2(2.2)$ & $13.0(2.6)$ & - & - & $6600.0(278)$ & - & 0.737 \\
\hline Median (IQR) & $13.0(12.0-15.0)$ & $13.0(11.0-15.0)$ & - & - & - & - & - \\
\hline \multicolumn{8}{|l|}{ Attitudes (0-68) } \\
\hline Mean (s.d.) & $32.9(6.5)$ & $32.8(6.5)$ & - & - & $6432.0(268)$ & - & 0.962 \\
\hline Median (IQR) & $31.0(29.0-37.0)$ & $32.0(28.0-37.0)$ & - & - & - & - & - \\
\hline
\end{tabular}

psychologists showed higher levels of factual DVA knowledge. The odds ratio of 3.14 indicates a large effect (i.e. the odds of a psychologist scoring above median on the factual knowledge test was more than three times higher than the odds of a psychiatric nurse scoring above median). No differences were found between psychiatric nurses and the other MHC clinicians (i.e. psychiatrists, nurses and social workers)

However, our multivariate analysis showed that the clinician's discipline was no longer a contributing factor. Longer years of work remained a significant negative predictor for factual knowledge (Table 3). Age was not included in this multivariate analysis since age and years of professional experience are highly correlated $(r=0.78)$.

Table 4 reports the association with the subscale of DVA attitudes (i.e. attitudes regarding victim understanding, self-efficacy and staff preparedness). Older clinicians showed a higher score on this subscale. Psychologists, general nurses and social workers more often reported a lower score on attitudes than psychiatric nurses did, suggesting that they felt less empathy and understanding of the victim's situation and felt less ready to actively address the situation. The effect was large; psychiatric nurses had a two to three times higher odds of a high attitudes score. Psychiatrists also reported higher scores on attitude, but not significantly so. Clinicians who have previously attended training on domestic violence also scored higher on the attitudes scale. In a multivariate model, the effect of previous training and discipline remained. The effect of age was no longer significant.

\section{Discussion}

\section{Main findings}

This study is the first in the Netherlands to investigate associations between characteristics of clinicians working in mental health services and their knowledge, skills and attitude on DVA. Overall, clinicians rated their perceived skills and perceived knowledge on DVA as low. However, primary MHC clinicians felt more skilled to handle DVA in their patients and rated their knowledge as higher compared with clinicians working with patients with SMI. Although no official scoring norms for the survey exist, MHC clinicians showed high scores with regards to factual DVA knowledge, and medium scores with regards to attitudes. Professionals working in primary MHC and SMI care reported similar levels of DVA knowledge and attitudes.

Based on univariate and multivariate analyses, several clinician characteristics were associated with skills, knowledge and attitude. Clinicians working in primary MHC, who were responsible for a medium-sized case-load, and clinicians that previously attended a training course on DVA felt most skilled to handle individuals who have experienced DVA. On the other hand, younger, less experienced clinicians and psychologists showed higher levels of factual knowledge on DVA. Psychiatric nurses and clinicians previously trained on DVA showed the most supportive attitudes towards victims of DVA and readiness to manage DVA. Overall, self-rated knowledge and skills to manage DVA were highly 
Table 2 Univariate and multivariate predictors of perceived skills to manage domestic violence and abuse

\begin{tabular}{|c|c|c|}
\hline Characteristic & OR & $95 \% \mathrm{Cl}$ \\
\hline \multicolumn{3}{|l|}{ Univariate } \\
\hline \multicolumn{3}{|l|}{ Gender } \\
\hline Men & 0.81 & $0.48-1.34$ \\
\hline Women & 1 & - \\
\hline Age & 1.01 & $0.99-1.03$ \\
\hline \multicolumn{3}{|l|}{ Discipline } \\
\hline Psychiatric nurse & 1 & - \\
\hline Psychiatrist or resident & 1.57 & $0.59-4.18$ \\
\hline Psychologist & 2.05 & $0.88-4.77$ \\
\hline Nurse & 0.75 & $0.35-1.61$ \\
\hline Social worker & 0.70 & $0.27-1.84$ \\
\hline Other & 0.82 & $0.32-2.09$ \\
\hline Years of professional experience & 1.01 & $0.99-1.04$ \\
\hline \multicolumn{3}{|l|}{ Case-load } \\
\hline $0-39$ & 0.53 & $0.30-0.94^{*}$ \\
\hline $40-59$ & 1.59 & $0.83-3.07$ \\
\hline$\geq 60$ & 1 & - \\
\hline \multicolumn{3}{|l|}{ Training in domestic violence (ever) } \\
\hline Yes & 3.63 & $1.88-7.02^{*}$ \\
\hline No & 1 & - \\
\hline \multicolumn{3}{|l|}{ Mental healthcare service } \\
\hline Primary care & 5.64 & $2.93-10.86^{*}$ \\
\hline Severe mental illness care & 1 & - \\
\hline \multicolumn{3}{|l|}{ Multivariate } \\
\hline \multicolumn{3}{|l|}{ Case-load } \\
\hline $0-39$ & 0.82 & $0.44-1.55$ \\
\hline $40-59$ & 2.11 & $1.03-4.34^{*}$ \\
\hline$\geq 60$ & 1 & - \\
\hline \multicolumn{3}{|l|}{ Training in domestic violence } \\
\hline Yes & 3.00 & $1.49-6.16^{*}$ \\
\hline No & 1 & - \\
\hline \multicolumn{3}{|l|}{ Mental healthcare service } \\
\hline Primary care & 5.14 & $2.55-10.33^{*}$ \\
\hline Severe mental illness care & 1 & - \\
\hline
\end{tabular}

intercorrelated. Correlations with factual knowledge and attitudes were much lower. This suggests that clinicians scoring high on perceived skills and knowledge do not necessarily have actual knowledge and appropriate attitudes regarding DVA, meaning that they may not be aware of limits in their competence. This is particularly the case in our study for older clinicians.

\section{Interpretation of our findings and comparison with findings from other studies}

Trained MHC clinicians felt more knowledgeable and skilled to handle individuals who had experienced DVA. The impact of previous DVA training on self-confidence to handle DVA is supported by findings of previous studies among MHC professionals in the UK, USA and Australia ${ }^{25,32,33}$ and paramedic students. ${ }^{34}$ All studies concluded that the level of knowledge, skills and preparedness on DVA of MHC clinicians needs improvement. Clinicians with a larger case-load might feel more skilled because of more extensive hands-on experience they might have had with victims of DVA. More clinicians in primary MHC had attended DVA training, and primary MHC clinicians have a substantially larger caseload. However, the results from our multivariate analysis showed that these factors only partially explained why clinicians working with patients with SMI feel less comfortable in handling DVA in their patients. We suggest that the complex presentation of patients with SMI makes it difficult to assess reports of DVA in the context of acute psychopathology, psychosocial difficulties, time constraints and management challenges. Time constraints are an additional
Table 3 Univariate and multivariate predictors of factual knowledge on domestic violence and abuse

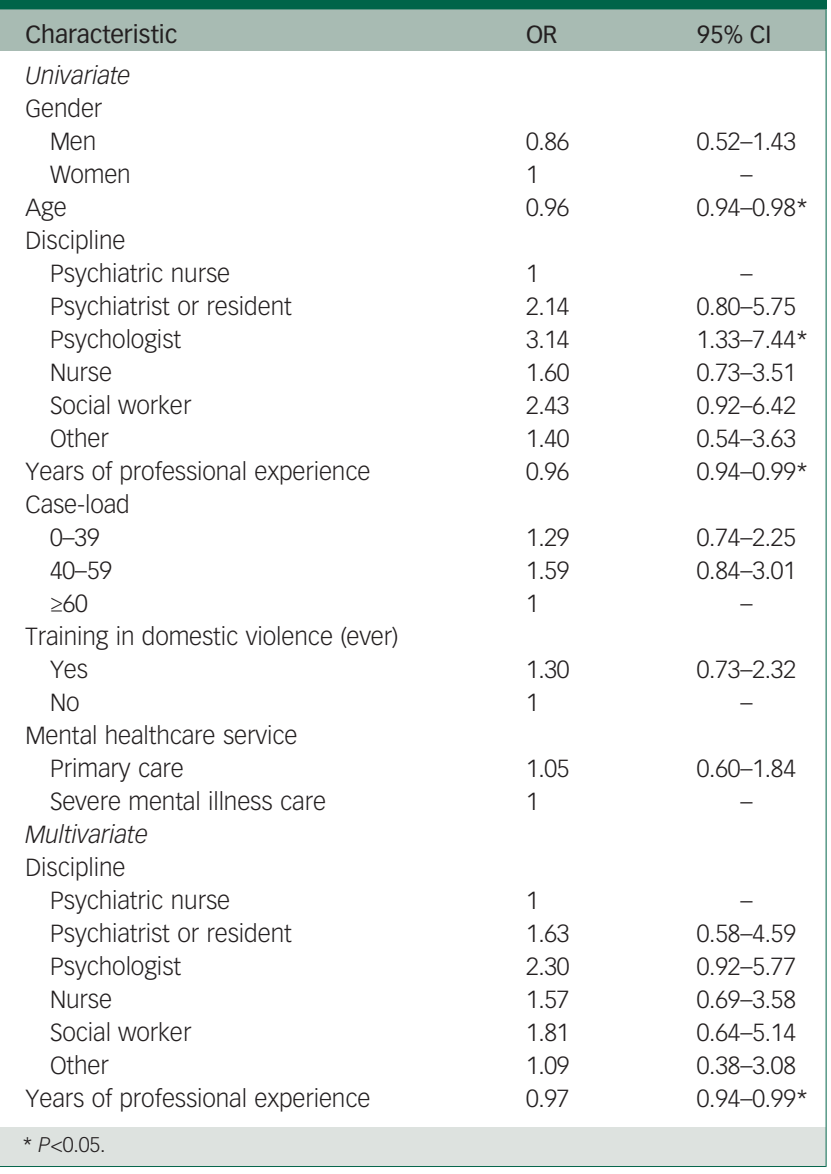

important barrier for identification of DVA ${ }^{19,35}$ and might therefore lower instead of increase the chance of hands-on DVA experience.

Fewer years of work was associated with higher levels of factual knowledge of DVA. On average, these were younger MHC professionals who have just finished or were still in the process of finalising their professional education. This reflects changes in education and awareness about DVA. ${ }^{20,36}$ The psychologists, who routinely are taught how to address trauma and victimisation, not surprisingly had higher factual knowledge. More recently, in response to political attention about DVA, the topic is increasingly incorporated into a whole spectrum of clinical training programmes, which might also have been a contributing factor. However, as shown by Nyame and colleagues, ${ }^{25}$ greater factual knowledge does not necessarily translate into readiness to address DVA or an increase in referral rates to specialised DVA services among UK MHC professionals. ${ }^{37}$ Clinical training programmes should therefore focus on developing skills as well as provision of knowledge; indeed the World Psychiatric Association has recently published a competency curriculum on domestic and sexual violence. ${ }^{38}$ This finding also highlights the necessity of including this topic in in-service training programmes required by clinical professionals in order to secure their professional licence or hospital privileges, for instance by means of an annual web course and short quiz.

Overall, attitudes towards victims of DVA and responsibility in handling DVA was positively associated with training. The discipline of staff was also associated with scores, with psychologists and general nurses having lower scores, and psychiatric nurses higher scores. This scale is an aggregation of statements regarding victim understanding, self-efficacy and staff preparations. Taken together, the scale reflects the willingness or likelihood that a 
Table 4 Univariate and multivariate predictors of attitudes on domestic violence and abuse

\begin{tabular}{|c|c|c|}
\hline Characteristic & OR & $95 \% \mathrm{Cl}$ \\
\hline \multicolumn{3}{|l|}{ Univariate } \\
\hline \multicolumn{3}{|l|}{ Gender } \\
\hline Men & 1.10 & $0.66-1.84$ \\
\hline Women & 1 & - \\
\hline Age & 1.02 & $1.00-1.05^{*}$ \\
\hline \multicolumn{3}{|l|}{ Discipline } \\
\hline Psychiatric nurse & 1 & - \\
\hline Psychiatrist or resident & 1.26 & $0.43-3.66$ \\
\hline Psychologist & 0.40 & $0.17-0.95^{*}$ \\
\hline Nurse & 0.39 & $0.17-0.88^{*}$ \\
\hline Social worker & 0.37 & $0.14-0.99 *$ \\
\hline Other & 0.58 & $0.22-1.56$ \\
\hline Years of professional experience & 1.02 & $0.99-1.04$ \\
\hline \multicolumn{3}{|l|}{ Case-load } \\
\hline $0-39$ & 0.69 & $0.39-1.21$ \\
\hline $40-59$ & 1.33 & $0.69-2.56$ \\
\hline$\geq 60$ & 1 & - \\
\hline \multicolumn{3}{|l|}{ Training in domestic violence (ever) } \\
\hline Yes & 2.35 & $1.27-4.37 *$ \\
\hline No & 1 & - \\
\hline \multicolumn{3}{|l|}{ Mental healthcare service } \\
\hline Primary care & 0.87 & $0.50-1.53$ \\
\hline Severe mental illness care & 1 & - \\
\hline \multicolumn{3}{|l|}{ Multivariate } \\
\hline Age & 1.01 & $0.99-1.03$ \\
\hline \multicolumn{3}{|l|}{ Discipline } \\
\hline Psychiatric nurse & 1 & - \\
\hline Psychiatrist or resident & 1.34 & $0.45-4.01$ \\
\hline Psychologist & 0.36 & $0.14-0.93^{*}$ \\
\hline Nurse & 0.39 & $0.17-0.90^{*}$ \\
\hline Social worker & 0.41 & $0.14-1.19$ \\
\hline Other & 0.65 & $0.23-1.84$ \\
\hline \multicolumn{3}{|l|}{ Training in domestic violence (ever) } \\
\hline Yes & 2.71 & $1.40-5.25^{*}$ \\
\hline No & 1 & - \\
\hline
\end{tabular}

community MHC professional will take a pro-active attitude in the detection and handing of an individual's case, and support of a victim. To better understand the attitude of psychologists and general nurses we examined which items were scored particularly low, and found that professionals from these disciplines reported especially low scores on self-efficacy compared with other professions. This is in accordance with previous research, ${ }^{39}$ which found that general nurses working in primary healthcare on average had less understanding for victims, and felt less prepared and self-efficacious to manage DVA than medical doctors did. The reason for this difference between nurses and doctors remained unclear, but it was speculated that nurses are less experienced in the role of diagnosis and referrals to specialist services. ${ }^{39}$

\section{Strengths and limitations}

This cross-sectional study is the first large scale study on DVA knowledge and opinions in MHC practitioners in the Netherlands. The response rate in our study was high $(78 \%),{ }^{40}$ which suggests that our sample is representative of the participating MHC services, and might be generalised to all out-patient MHC workers in this area. However, the highly urbanised and culturally diverse context of this area compared with more rural parts of the Netherlands might limit the generalizability of the results. Other studies have reported that cultural background influences the attitudes and opinions on DVA of clinicians. ${ }^{19,41}$

We used a survey specifically developed for the Dutch community mental health context to assess readiness to manage DVA in patients with psychiatric conditions. The resulting instrument was relevant to the context, and relatively short, which might have contributed to our high response rate. In the absence of a gold-standard questionnaire to assess DVA-readiness, the psychometric properties in terms of test-retest reliability and internal consistency were sufficient to good. The assessed attitudes on DVA were heterogeneous in nature, which might have caused the less optimal psychometric qualities of this specific subscale. The survey was informed by two validated questionnaires, ${ }^{24,26}$ thereby ensuring consistency with other DVA-readiness questionnaires used in healthcare. The predictive value of this questionnaire in relationship to actual and effective support of victims and management of DVA in healthcare is still unknown. However, since this study is part of a longitudinal trial on DVA management by MHC professionals, we hope future analysis will provide better insight. ${ }^{22}$

\section{Implications and future directions}

This study shows that training in DVA is likely associated with greater levels of perceived skills, knowledge and attitudes towards DVA management. We suggest that follow-up training and longterm support of the staff and clinicians is necessary to ensure development and retention of obtained knowledge and skills. Based on our analyses, we conclude that DVA training would be most effective when provided to community MHC professionals and professionals who have been working in services longest. Although we expect that such training would lead to an increase in professionals' readiness to handle DVA, more research is needed to investigate whether this training also results in more identification, prevention and intervention activities and eventually in a reduction of DVA in patients with psychiatric conditions and better patient outcomes.

Roos E. Ruijne, MD ID, PhD Candidate, Epidemiological and Social Psychiatric Research Institute, Department of Psychiatry, Erasmus University Medical Centre Rotterdam, the Netherlands; Astrid M. Kamperman, PhD, Epidemiologist, Assistant Professor,

Epidemiological and Social Psychiatric Research Institute, Department of Psychiatry, Erasmus University Medical Centre Rotterdam, the Netherlands; Kylee Trevillion, PhD, Lecturer, Research Fellow, Section of Women's Mental Health, Institute of Psychiatry, Psychology \& Neuroscience, King's College London, UK; Carlo Garofalo, PhD, Assistant Professor, Department of Developmental Psychology, Tilburg University; and Fivoor Science \& Treatment Innovation, the Netherlands; Femke E. Jongejan, MSc, Research Assistant, Epidemiological and Social Psychiatric Research Institute, Department of Psychiatry, Erasmus University Medical Centre Rotterdam, the Netherlands; Stefan Bogaerts, PhD, Professor of Social and Behavioral Sciences, Department of Developmental Psychology, Tilburg University; and Fivoor Science \& Treatment Innovation, the Netherlands; Louise M. Howard, MD, PhD, NIHR Research Professor, Professor in Women's Mental Health, Consultant Perinatal Psychiatrist, Section of Women's Mental Health, Institute of Psychiatry, Psychology \& Neuroscience, King's College London, UK; Niels L. Mulder, MD, PhD, Professor in Public Mental Health, Psychiatrist, Epidemiological and Social Psychiatric Research Institute, Department of Psychiatry, Erasmus University Medical Centre Rotterdam; and Bavo Europoort Menta Healthcare Organization, the Netherlands

Correspondence: Roos E. Ruijne, Epidemiological and Social Psychiatric Research Institute, Department of Psychiatry, Erasmus University Medical Centre Rotterdam, Dr. Molenwaterplein 40, 3015 GD Rotterdam, the Netherlands. Email: r.ruijne@erasmusmc.nl

First received 7 Nov 2018, final revision 23 Jan 2019, accepted 25 Jan 2019

\section{Funding}

This project received a grant from the Netherlands Scientific Organization: Grant number: 43213-803.

\section{Acknowledgements}

The authors would like to thank all the mental healthcare professionals participating in this survey.

Data are stored at the institutional database of the Erasmus Medical Centre in Rotterdam, the Netherlands. The data-sets on which the analyses are based are available on request to the Local Ethics Committee of the Erasmus Medical Centre in Rotterdam, due to ethical restriction and respondent confidentiality requirements. To request the data, please contact the author. 


\section{References}

1 Ellsberg $\mathrm{M}$, Jansen $\mathrm{HA}$, Heise L, Watts $\mathrm{CH}$, Garcia-Moreno C. Intimate partner violence and women's physical and mental health in the WHO multi-country study on women's health and domestic violence: an observational study. Lancet 2008; 371: 1165-72.

2 Stuurgroep multidisciplinaire richtlijnontwikkeling in de GGZ. [Advisory committee multidisciplinary guideline development in mental health care.] Familiaal Huiselijk Geweld, Trimbos Instituut, 2009.

3 World Health Organization. Understanding and Addressing Violence Against Women: Intimate Partner Violence. World Health Organization, 2012 (apps.who.int/iris/bitstream/handle/10665/77432/WHO_RHR_12.36_eng.pdf? sequence $=1$ ).

4 Capaldi DM, Knoble NB, Shortt JW, Kim HK. A systematic review of risk factors for intimate partner violence. Partner Abuse 2012; 3: 231-80.

5 Dearwater SR, Coben JH, Campbell JC, Nah G, Glass N, McLoughlin E, et al. Prevalence of intimate partner abuse in women treated at community hospita emergency departments. JAMA 1998; 280: 433-8.

6 Jones AS, Gielen AC, Campbell JC, Schollenberger J, Dienemann JA, Kub J, et al. Annual and lifetime prevalence of partner abuse in a sample of female HMO enrollees. Womens Health Issues 1999; 9: 295-305

7 McCauley J, Kern DE, Kolodner K, Dill L, Schroeder AF, Dechant HK, et al. The 'battering syndrome': prevalence and clinical characteristics of domestic violence in primary care internal medicine practices. Ann Intern Med 1995; 123 737-46.

8 Oram S, Khalifeh H, Howard LM. Violence against women and mental health. Lancet Psychiatry 2017; 4: 159-70.

9 Kamperman AM, Henrichs J, Bogaerts S, Lesaffre EM, Wierdsma Al, Ghauharali RR, et al. Criminal victimisation in people with severe mental illness: a multi-site prevalence and incidence survey in the Netherlands. PLOS One 2014; 9: e91029.

10 Campbell JC. Health consequences of intimate partner violence. Lancet 2002 359: 1331-6.

11 Reid RJ, Bonomi AE, Rivara FP, Anderson ML, Fishman PA, Carrell DS, et al Intimate partner violence among men. prevalence, chronicity, and health effects. Am J Prev Med 2008; 34: 478-85.

12 Kunst MJ, Winkel FW, Bogaerts S. Posttraumatic anger, recalled peritraumatic emotions, and PTSD in victims of violent crime. J Interpers violence 2011; 26: 3561-79.

13 Golding JM. Intimate partner violence as a risk factor for mental disorders: a meta-analysis. J Fam Viol 1999; 14: 99-132.

14 Devries KM, Mak JY, Bacchus LJ, Child JC, Falder G, Petzold M, et al. Intimate partner violence and incident depressive symptoms and suicide attempts: a systematic review of longitudinal studies. PLOS Med 2013; 10: e1001439.

15 Read J, Fraser A. Staff response to abuse histories of psychiatric inpatients. Aust N Z J Psychiatry 1998; 32: 206-13.

16 Feder G, Davies RA, Baird K, Dunne D, Eldridge S, Griffiths C, et al. Identification and referral to improve safety (IRIS) of women experiencing domestic violence with a primary care training and support programme: a cluster randomised controlled trial. Lancet 2011; 378: 1788-95.

17 Trevillion K, Byford S, Carey M, Rose D, Oram S, Feder G, et al. Linking abuse and recovery through advocacy: an observational study. Epidemiol Psychiatr Sci 2014; 23: 99-113.

18 Read J, Hammersley P, Rudegeair T. Why, when and how to ask about childhood abuse. Adv Psychiatr Treat 2007; 13: 101-10.

19 Rose D, Trevillion K, Woodall A, Morgan C, Feder G, Howard LM. Barriers and facilitators of disclosure of domestic violence by mental health service users: qualitative study. Br J Psychiatry 2011; 198: 189-94.

20 Stewart DE, Chandra PS. WPA international competency-based curriculum for mental health providers on intimate partner violence and sexual violence against women. World Psychiatry 2017; 16: 223-4.

21 Royal Dutch Medical Association. KNMG-Meldcode Kindermishandeling en Huiselijk Geweld. [KNMG-Reporting Guideline of Child Abuse and Domestic Violence and Abuse.] Koninklijke Nederlandsche Maatschappij tot Bevordering der Geneeskunst, 2015.
22 Ruijne RE, Howard LM, Trevillion K, Jongejan FE, Garofalo C, Bogaerts S, et al. Detection of domestic violence by community mental health teams: a multicenter, cluster randomized controlled trial. BMC Psychiatry 2017; 17: 288

23 Stein LI, Test MA. Alternative to mental hospital treatment. I. Conceptual model, treatment program, and clinical evaluation. Arch Gen Psychiatry 1980; 37: 392-7.

24 Short LM, Alpert E, Harris JM, Surprenant ZJ. A tool for measuring physician readiness to manage intimate partner violence. Am J Prev Med 2006; 30: 173-80.

25 Nyame S, Howard LM, Feder G, Trevillion K. A survey of mental health professionals' knowledge, attitudes and preparedness to respond to domestic violence. J Ment Health 2013; 22: 536-43.

26 Ross C, Dimitrova S, Howard LM, Dewey M, Zimmerman C, Oram S. Human trafficking and health: a cross-sectional survey of NHS professionals' contact with victims of human trafficking. BMJ Open 2015; 5: e008682.

27 van Knippenberg FCE, Duivenvoorden HJ, Bonke B, Passchier J. Shortening the state-trait anxiety inventory. J Clin Epidemiol 1990; 43: 995-1000.

28 Heilbronner RL, Sweet JJ, Attix DK, Krull KR, Henry GK, Hart RP. Official position of the American Academy of Clinical Neuropsychology on serial neuropsychological assessments: the utility and challenges of repeat test administrations in clinical and forensic contexts. Clin Neuropsychol 2010; 24: 1267-78.

29 Frasier PY, Slatt L, Kowlowitz V, Glowa PT. Using the stages of change model to counsel victims of intimate partner violence. Patient Educ Couns 2001; 43: 211-7

30 Miller MB. Coefficient alpha: a basic introduction from perspectives of classical test theory and structural equation modelling. Struct Equ Model 1995; 2: 255-73.

31 Cohen J. The earth is round ( $\mathrm{p}<0.05)$. Am Psychol 1994; 49: 997-1003.

32 Forsdike K, O'Connor M, Castle D, Hegarty K. Exploring Australian psychiatrists' and psychiatric trainees' knowledge, attitudes and preparedness in responding to adults experiencing domestic violence. Australas Psychiatry 2018; Jul 26 (Epub ahead of print).

33 Murray CE, Davis J, Rudolph L, Graves KN, Colbert R, Fryer M, et al. Domestic violence training experiences and needs among mental health professionals: implications from a statewide survey. Violence Vict 2016; 31: 901-20.

34 Sawyer S, Coles J, Williams A, Lucas P, Williams B. Paramedic students' knowledge, attitudes, and preparedness to manage intimate partner violence patients. Prehosp Emerg Care 2017; 21: 750-60.

35 Sprague S, Madden K, Simunovic N, Godin K, Pham NK, Bhandari M, et al. Barriers to screening for intimate partner violence. Women Health 2012; 52: 587-605.

36 van Beek I, Bosdriesz M, Knaap M, Korfker D, Meeuwissen I, Ouwehand L-M et al. Aandacht voor Huiselijk Geweld en Kindermishandeling. Hoe Zijn Geweldsthema's verwerkt in de Onderwijsprogramma's van SociaalAgogische, Pedagogische, Psychologische, Zorg- en Onderwijsopleidingen? Een inventarisatie. [Taking Notice of Domestic Violence and Child Abuse. How are Topics on Violence Embedded in Educational Programs for Social Workers, Educationists, Psychologists, Health Care Workers and Teachers? An Overview.] Nederlands Jeugdinstituut, 2013.

37 Forsdike K, Humphreys C, Diemer K, Ross S, Gyorki L, Maher H, et al. An Australian hospital's training program and referral pathway within a multidisciplinary health-justice partnership addressing family violence. Aust $N \mathrm{Z} \mathrm{J}$ Public Health 2018; 42: 284-90.

38 Stewart DE, Chandra PS. The World Psychiatric Association (WPA) International Competency-Based Curriculum for Mental Health Care Providers on Intimate Partner Violence/Sexual Violence Against Women. World Psychiatric Association, 2016 (http://www.wpanet.org/uploads/Latest_News/News from WPA_Sections/WPA_IPV_SV_Curriculam.pdf)

39 Ramsay J, Rutterford C, Gregory A, Dunne D, Eldridge S, Sharp D, et al. Domestic violence: knowledge, attitudes, and clinical practice of selected UK primary healthcare clinicians. Br J Gen Pract 2012; 62: e647-55.

40 Bowling A. Data Collection Methods in Quantitative Research: Questionnaires, Interviews and Their Response Rates. Open University Press, 1997.

41 Usta J, Feder G, Antoun J. Attitudes towards domestic violence in Lebanon: a qualitative study of primary care practitioners. Br J Gen Pract 2014; 64: e313-20. 